\title{
GUEST LECTURE STRABISMUS: CHALLENGES AND TRENDS
}

\author{
TONY MURRAY \\ Cape Town, South Africa
}

Strabismus in its various forms presents numerous challenges, many of which are today being met more appropriately because of recent trends in management of the condition.

\section{INFANTILE ESOTROPIA}

\section{Early Treatment}

The challenge of treating patients with infantile esotropia, so that they achieve stable long-term alignment with good vision in each eye and some degree of binocular single vision, remains a formidable one. The condition is not congenital, and is not present at birth, but develops between 1 and 6 months of age. ${ }^{1,2}$ A growing body of evidence supports the potential for the development of some form of binocularity if appropriate ocular alignment is achieved early in life. ${ }^{3-7}$ The best result that can be expected is a monofixational syndrome with a residual small angle of esotropia and peripheral fusion ${ }^{7,8}$ Bifoveal (central) fusion is hardly, if ever, achieved. ${ }^{7,9}$ If alignment is achieved after 24 months of age the degree of binocularity diminishes. ${ }^{3,7}$ Patients with a stable moderate to large angle with no refractive error, equal vision and habitual alternation can anticipate a good binocular result when surgically aligned at about 18 months of age. In the presence of unequal vision, a significant amount of corrected hypermetropia, any uncorrected hypermetropia, a small variable angle or minimal brain dysfunction, a poor binocular result can be expected. ${ }^{10}$

Early development and maintenance of binocular vision increases the likelihood that ocular alignment will be maintained on a long-term basis. ${ }^{11}$ Visual motion processing, the ability to sense the speed and direction of moving objects based on retinal slip signals, plays an everincreasing role in our understanding of strabismus. Abnormalities of visual motion processing manifest with asymmetrical monocular optokinetic nystagmus (OKN) and asymmetrical visual evoked potentials (VEP). ${ }^{12,13}$

Correspondence to: A. D. N. Murray, FRCS (Edin) FCOphth, Department of Ophthalmology, University of Cape Town Medical School, Observatory, 7925, Cape Town, South Africa.
Normal infants between birth and 2 months of age demonstrate abnormal motion processing which normalises by about 6 months of age. However, if infantile esotropia is present this abnormality frequently persists. Should surgical alignment take place before 24 months of age this asymmetry becomes symmetrical, ${ }^{14}$ providing further evidence in favour of early detection, assessment and alignment. In order to initiate treatment sufficiently early, involved individuals should be examined by an ophthalmologist at the earliest opportunity, while their siblings and offspring should, if possible, be examined at about 3 months of age, even if strabismus is not apparent. Yet despite the efforts of school screening programmes and public awareness campaigns, many patients still present too late. How can early assessment be ensured? Photorefraction using photoscreen devices is simple and relatively inexpensive, and can reliably detect slight differences between the red reflexes of each eye. ${ }^{15,16}$ These changes occur in almost all patients with strabismus or refractive errors, and in the foreseeable future a single photograph of a group of young infants may well be all that is necessary to identify those with these conditions. The trend will surely be to use these instruments on a much wider scale.

\section{Cover Tests and Occlusion}

Cover tests remain the foundation of all strabismus testing. In younger children appropriate distance fixation targets are required. Foot-controlled, motorised targets are ideal. ${ }^{17}$ Cover tests detect the presence and magnitude of a deviation and are also especially useful for determining the level of visual acuity related to the fixation pattern of pre-verbal children. ${ }^{18}$

When amblyopia exists, occlusion should be instituted before surgery takes place,,$^{19}$ but the question is precisely how much therapeutic occlusion is appropriate. Is parttime intermittent occlusion adequate, or should occlusion be enforced during all the waking hours? If an infant with esotropia alternates freely and habitually, is any occlusion necessary before surgery? Full-time alternate occlusion of 
patients with infantile esotropia has been advocated as a strategy for delaying or preserving potential binocularity. ${ }^{18}$ Indirect clinical evidence suggests a beneficial role for alternate occlusion therapy ${ }^{20}$ but direct evidence as to the nature of the effect of occlusion, or its mechanism of action, has been lacking. A recent report, which adds support to the clinical impression, demonstrates that preoperative full-time alternate occlusion per se produces normal or markedly improved motion processing in infants with esotropia. ${ }^{21}$ The authors suggest that the binocular motion system is disrupted by abnormal binocular interactions that develop in association with strabismus. Full-time alternate occlusion may prevent these abnormal interactions from occurring, thereby allowing the motor system to develop along what might be a genetically determined time course. Binocular stimulation may not be an essential requirement early on, and it is possible that alternate occlusion may 'keep the slate clean' and maintain the innate binocular visual potential which will then respond to binocular stimulation at a later stage. Further analysis of the effects of alternate occlusion may well lead to its use on a much wider scale.

\section{Amount of Surgery}

Re-operation rates of close to $50 \%$ following 'standard' amounts of two-muscle surgery have led to a trend to perform either selective surgery on three or four muscles ${ }^{20,22}$ or larger recessions of both medial recti. ${ }^{23-27}$ Ciancia was one of the pioneers in this respect, and in 1962 proposed that infants with early-onset large angle esotropia, who prefer to fix in adduction because of latent nystagmus which is most marked in abduction, require larger amounts of recession of the medial recti than those infants with esotropia without these features. ${ }^{23}$ Large medial rectus recessions are quicker and easier to accomplish than three- or four-muscle surgery, and achieve alignment with one operation in up to $80 \%$ of patients. ${ }^{25}$ Although there was concern that limitation of adduction and convergence and late exotropia would result, to date this has not been reported. It is easier and safer to perform large recessions by using 'hangback' sutures whereby the muscle is reattached to the sclera at the original muscle insertion and not at the new recession site. This reduces the risk of scleral perforation and the effect has proved to be very similar to that achieved using standard procedures. ${ }^{28-31}$

\section{Natural History}

The natural course of untreated infantile esotropia is unknown. We attempted to establish the prevalence of strabismic amblyopia in 142 patients with a history of early-onset esotropia who had reached visual adulthood without any form of treatment. ${ }^{32,33}$ The presence or absence of dissociated vertical deviation (DVD), latent nystagmus (LN) and anomalous optokinetic nystagmus $(\mathrm{OKN})$, regarded as three salient features suggestive of infantile esotropia, were specifically determined in an effort to confirm the diagnosis of the condition. Of the whole group of 142 patients, only $9(6.3 \%)$ had strabismic amblyopia. Of the 142,113 had either DVD, LN or anomalous OKN alone or in combination, and of these only 3 (2.6\%) had strabismic amblyopia. Of the 29 patients who had a history of infantile esotropia but no suggestive features, $6(21 \%)$ had strabismic amblyopia. In comparison, $70 \%$ of infantile esotropes surgically aligned before 1 year of age required long-term, part-time occlusion to maintain good visual acuity, ${ }^{34}$ and of a group of 31 patients, $4(13 \%)$ had amblyopia pre-operatively whereas $19(61 \%)$ had amblyopia after surgery. ${ }^{35}$ In two other series, despite careful follow-up post-operatively, amblyopia persisted in $50 \%$ and $46 \%$ respectively. ${ }^{3,8}$ Thus, even with careful and frequent follow-up by experienced clinicians, a considerable proportion of patients with infantile esotropia develop a significant degree of amblyopia after surgical alignment, whereas if these patients remain untreated the risk of strabismic amblyopia is much lower. Whenever inadequate follow-up is anticipated, one has to weigh up the advantages of early alignment, which will produce some degree of binocular single vision and stability but also some risk of amblyopia, with delaying surgery until the patient is a visual adult, accepting a lesser degree of binocular single vision but a smaller risk of amblyopia. ${ }^{32}$

Although their potential for binocular vision is usually reduced, some patients with infantile esotropia may obtain a functionally useful form of binocular vision when aligned as visual adults. ${ }^{7}$ A pre-operative botulinum toxin adaptation test can be used to predict their binocular potential, thereby determining whether undercorrection or alignment should be the surgical goal. ${ }^{36,37}$ Most untreated infantile esotropes do not develop useful binocular vision after late surgical alignment, but nevertheless derive functional benefit from expansion of their binocular field. The temporal crescents, which are seen monocularly by each eye, form $33 \%$ of the visual field and are not affected by suppression amblyopia. Even patients who have 'deep ' amblyopia achieve a larger binocular field after reduction of their angle of esotropia. ${ }^{38}$

\section{Subgroups}

It is possible that infantile esotropia may consist of two distinct subgroups: one consisting of those with DVD, LN and asymmetrical OKN, and the other made up of those without these features. ${ }^{7,23,32,33,39}$ These two subgroups may have a different pathophysiology and prognosis. Of 80 similar patients who were surgically aligned within 8 prism dioptres of orthotropia, 38 developed a monofixational syndrome (MFS) and 42 had no evidence of monofixation. ${ }^{11}$ The reason why some patients develop a MFS and others do not is unknown. Do the patients who develop a MFS have the potential to develop fusion as an overt motor response acquired by usage as proposed by Chavasse, and do those who do not develop a MFS comprise a different subgroup who have an inborn defect of the fusion faculty as proposed by Worth $?^{40}$ The answers to these questions are not known, but both Chavasse and Worth may well prove to be correct. 


\section{Botulinum Toxin}

The role of botulinum in infantile esotropia will be discussed later.

\section{DISSOCIATED VERTICAL DEVIATION (DVD)}

Large superior rectus recessions are currently the preferred surgical method of treating DVD, with a success rate of $72 \% .^{41}$ Anterior transposition of the inferior oblique to a position either adjacent to the insertion of the inferior rectus, or between the insertion of the inferior rectus and the limbus, converts the action of the inferior oblique from that of an elevator to that of a depressor. ${ }^{42}$ This has proved to be safe and effective in reducing overaction of the inferior oblique, either as a primary procedure or after previous surgery, and also controls DVD. ${ }^{43,44}$ It may be the preferred option when DVD and inferior oblique overaction coexist. ${ }^{45}$

\section{ACCOMMODATIVE ESOTROPIA}

Retinoscopy, like chess, is easy to learn but difficult to master, and both skill and experience are needed to determine accurately the refraction of an infant or a child. To ensure that the appropriate spectacle or contact lens correction is worn by the young is a challenging exercise. In order to avoid test-induced errors, retinoscopy must be performed along the visual axis because misalignment of even $10^{\circ}$ can lead to a cylindrical error of up to 2 dioptres. ${ }^{46,47}$ Any anisometropia is important, as even small amounts may act as a 'trigger', leading to a breakdown in fusion with a resultant deviation. ${ }^{18}$ Fully accommodative esotropia should be treated with appropriate lenses as determined by cycloplegic refraction with atropine or cyclopentolate. ${ }^{48-51}$ When partially accommodative esotropia (esotropia with an accommodative element) is present, lenses are used to control the accommodative element and surgery is indicated for the residual deviation. ${ }^{49}$

An opposing viewpoint emphasises that only a small proportion of hypermetropic children develop esotropia, and postulates that those who do become esotropic also have some cyclovertical incomitance which acts as a barrier to fusion. Simultaneous recession of both medial recti, and 'desagittalisation' of the oblique muscles is thought to remove this barrier, and has been proposed in lieu of spectacles for both fully and partially accommodative esotropia. ${ }^{52-55}$ In a multicentre study in which this form of surgery was used, 639 of 794 patients $(80.5 \%)$ with V-pattern esotropia were adjudged to be aligned post-operatively without their spectacles when the horizontal angle was measured with a Maddox cross. ${ }^{56}$ However, the group was a mixed one and included patients with accommodative esotropia as well as patients with infantile esotropia. Also, the refractive error was reported in only 524 of these 794 patients (66\%), 174 (33\%) of whom had hypermetropia of 3 dioptres or more. A hypermetropic correction was required by 132 patients post-operatively, but which patients required the correction was not reported. It is possible that those requiring correction all had refractive errors of plus 3 dioptres or more, and the reported results do not appear to support the author's claim that the accommodative component disappears after desagittalisation surgery.

When tested without spectacles, 66 of 202 patients (32.7\%) with accommodative esotropia demonstrated a vertical deviation. ${ }^{55}$ However, in a prospective study of 53 patients with fully accommodative esotropia, all of whom had stable fusion, none had an A- or V-pattern or a coexisting vertical or cyclotropic deviation when examined with their refractive error corrected. When tested without their spectacles, and in the presence of a large angle esotropia, 36 of the $53(68 \%)$ demonstrated over- or under-action of the superior or inferior oblique muscles, and $7(13 \%)$ had an A- or V-pattern. These incomitancies were considered to be artefacts caused by fluctuations of the accommodative effort, which occur during measurement in different gaze positions when hypermetropia is uncorrected and when an appropriate fixation target is not used to control accommodation. Surgery on the oblique muscles under these conditions is contra-indicated. ${ }^{57}$ The concept of treating accommodative esotropia with simultaneous horizontal and oblique muscle surgery is not generally accepted. Nevertheless recent advances in our understanding of the fast phasic and slower adaptable tonic responses of the accommodative convergence as well as the convergence accommodation mechanisms, ${ }^{51}$ suggest that further study of this group of patients is warranted; but accepted pre- and post-operative assessment criteria must be used. The treatment of choice for fully accommodative esotropia remains appropriate correction of the refractive error with spectacles or contact lenses. ${ }^{48-51,57}, 58$

\section{PRISM ADAPTATION}

The effectiveness of using pre-operative prisms in patients with acquired esotropia was studied in a prospective randomised multicentre clinical trial, in order to determine the maximum angle of strabismus and to estimate fusion potential. ${ }^{59}$ Two levels of randomisation were used. Sixty per cent of the patients underwent prism adaptation and $40 \%$ did not. Of those who responded to prisms with motor stability and sensory fusion, half underwent a conventional amount of surgery and half underwent augmented surgery based on the prism-adapted angle of deviation. The study yielded an overall success rate of $83 \%$ in prism-adapted patients. Prism responders had better results with augmented surgery than with conventional surgery (89\% [54/61] versus 79\% [53/67], $p=0.23)$, and success rates were lowest $(72 \%$, [92/127]) in those patients who did not undergo prism adaptation. The results indicate that prism adaptation better defines the target angle of surgery and results in a higher rate of satisfactory alignment without an increased risk of overcorrection. It is particularly useful for those patients who build up to larger angles and then undergo surgery for the adapted angle. 


\section{BOTULINUM TOXIN}

\section{Background}

Botulinum toxin chemodenervation of extraocular muscles with reasonable follow-up periods was first reported in $1981,{ }^{60}$ and has subsequently proved to be especially useful in meeting the challenge posed by some forms of strabismus. It can be performed as a brief office or outpatient procedure, carries minimal risk and leaves no scar. In order to localise injection of the toxin accurately, an electromyogram is used to guide a needle electrode into the desired muscle. The toxin produces a transient neuromuscular paralysis which starts 12-24 hours after injection, has a maximum effect at 10 days and usually lasts 2-3 months. The paralysed muscle lengthens and the ipsilateral antagonist, if functional, will with time develop some degree of contracture. The contracture persists after the transient paralysis of the injected muscle wears off, leading to a permanent change in ocular alignment. When used for paralytic strabismus of recent onset, botulinum paralysis of the antagonist muscle will prevent or reduce its contracture during spontaneous recovery of the paretic muscle. This is useful if onset of recovery in acute cases is delayed beyond 1 month, or to regain alignment in partially recovered palsies with residual strabismus. As with surgical treatment, the best results occur when fusion mechanisms are present to stabilise alignment.

Indications for the use of botulinum toxin therapy in strabismus are shown in Table I and disadvantages of the technique in Table II. ${ }^{61}$

\section{Results}

Three hundred and sixty-two children ranging in age from 2 months to 12 years were treated for strabismus by botulinum toxin injection of extraocular muscles. An average of 1.7 injections per patient was given, and the average follow-up was 26 months after the last injection. The frequency of correction to 10 prism dioptres (PD) or less was $61 \%(220 / 362)$ for all types of childhood strabismus, and $66 \%(238 / 362)$ for all childhood esotropia. Those with infantile esotropia were aligned $65 \%$ (235/362) of the time and smaller deviations of 10-20 PD were more frequently corrected $(73 \%)$ than larger deviations of 20-110 PD $(54 \%){ }^{62}$ Those results in attaining alignment within $10 \mathrm{PD}$ for infantile esotropia are comparable with those reported

Table I. Indications for botulinum toxin therapy in strabismus

For strabismic angles under 40 prism dioptres

For post-operative residual strabismus following surgery

For treatment of the antagonist in the acute phase of paralytic strabismus, or of the medial rectus in unrecovered sixth nerve palsy when combined with vertical muscle transposition

When strabismus surgery is rendered difficult by multiple prior strabismus operations, retinal detachment surgery or other procedures

When surgery is considered inappropriate, as in patients with preexisting conditions such as active dysthyroid myopathy, inflamed or pre-phthisical eyes, or where there is a risk of anterior segment ischaemia

For the non-accommodative component of accommodative esotropia To test the potential for binocular vision, or to test for diplopia for one strabismus operation correction using 'standard' amounts of surgery ${ }^{7,63}$ but are not as beneficial as those in recent reports when larger amounts of muscle surgery were used ${ }^{64-66}$ With further refinement, including bilateral injection, the use of antitoxin to prevent effects on the antagonist or adjacent muscles, and the treatment of younger children, it is possible that injection results may improve further for infantile esotropia. ${ }^{62}$ After injection, the infant develops a head turn, presumably because of some binocularity with the eyes aligned in that field of gaze. The hope that early alignment with this method would allow the infant to develop a better degree of binocular function has not materialised, and only 7 of 12 $(58 \%)$ demonstrated peripheral fusion and gross stereopsis, while none had bifoveal fusion. ${ }^{67}$ Botulinum treatment of children with exotropia was less impressive, only $45 \%$ achieving alignment within 10 PD of orthotropia. ${ }^{62}$

Two hundred and nineteen of 384 adults $(56 \%)$ with esotropia and 155 of 293 adults (52\%) with exotropia were aligned within $10 \mathrm{PD} .{ }^{61}$ These results are much less satisfactory than those achieved with adjustable suture surgery in similar groups of adult patients..$^{68-70}$

Vertical strabismus associated with thyroid eye disease was treated by injection of the inferior rectus in 27 potential surgical candidates, and although $11(41 \%)$ were adequately treated by one or more injections, $16(59 \%)$ eventually required surgery. Injection of the superior rectus always produces complete ptosis lasting more than 1 month, and oblique muscle injection alone is not highly effective. $^{61}$

All 9 patients with third nerve palsies that received lateral rectus injections recovered horizontal alignment and rotation. ${ }^{71}$ The role of botulinum toxin injection in treating lateral rectus palsies will be discussed later.

\section{Complications}

No systemic paralytic effect has been seen or suspected in any patient treated with the small doses used for eye muscle disease. Scleral perforation has, however, occurred in 9 of 8300 injections $(0.11 \%)$, although none of the 9 developed a retinal detachment, and only 1 patient had a reduction of vision of 1 line. Partial transitory ptosis was reported in $16 \%$ of adults and in $25 \%$ of children. An induced vertical deviation occurred in $17 \%$ of both adults and children, and persisted for 6 months or longer in $2 \% .^{61}$

Table II. Disadvantages of botulinum toxin therapy for strabismus

More than one injection is often needed to determine the optimum dose and thus obtain maximal benefit

Alignment change is not as stable as with surgery

One or two months of toxin-induced paralytic strabismus may create diplopia or spatial disorientation

Transient partial ptosis and vertical strabismus may occur as frequent side effects

Injection treatment is disappointing or will require multiple injections over time in patients with large deviations, restrictive strabismus or strabismus secondary to over-recessed muscles

Injection is ineffective as the sole treatment in chronic paralytic strabismus

Injection is difficult in vertical muscles other than the inferior rectus 


\section{SIXTH NERVE PALSY}

The sudden onset of a sixth nerve palsy usually results in debilitating horizontal diplopia. The temptation is to occlude only the involved eye, but this predisposes to medial rectus contracture, while occlusion of only the uninvolved eye results in past pointing and disturbed mobility. Occlusion of the involved eye as well as the placement of a 6-dioptre Fresnel prism, base out, before the normal eye, will force the normal eye to fix in adduction, and the motor apparatus will be directed towards the side of the paralysed lateral rectus muscle. The antagonist medial rectus is relaxed (according to Sherington's law of reciprocal innervation) and the risk of medial rectus contracture is reduced. ${ }^{72,73}$ However, the Fresnel prism blurs vision slightly and some patients find this form of treatment somewhat difficult to tolerate for prolonged periods. A similar objective can be achieved by totally occluding the involved eye and occluding the temporal half of the normal eye, forcing that eye to fix in adduction.

Only $49 \%$ of patients with sixth nerve palsy from all causes show spontaneous recovery and only $38 \%$ of cases occurring as a result of head trauma recover ${ }^{74}$ As some patients, including those with microvascular disease, will not recover spontaneously, and as this group cannot always be reliably identified in the acute stage, we now treat all patients who show no sign of sixth nerve recovery within a month of onset of the condition with botulinum toxin injection of the ipsilateral medial rectus ${ }^{75,76}$ Within a few days 7 of the first $8(87.5 \%)$ patients treated by us in this manner gained fusion without the necessity of a marked head turn and developed a centred field of binocular single vision, which even though of a small size, allowed them to read, watch television and cope with most activities. Despite the fact that their palsies were of traumatic origin, all 7 recovered full function. In two other similar series, 7 of $8(87.5 \%)$ and 18 of $20(90 \%)$ unilateral lateral rectus palsies recovered successfully following injection of the medial rectus, compared with 13 of 45 (29\%) palsies in an uninjected control group. ${ }^{71,77}$ In visually immature infants and children with sixth nerve palsies early injection with botulinum toxin must be considered in order to prevent amblyopia and the loss of binocularity. ${ }^{78}$

In the late stage, if partial recovery has taken place, alignment can be achieved with standard amounts of horizontal muscle surgery or with botulinum. If there is no recovery of sixth nerve function, as determined by the presence of a floating saccade and 'poor' force generation testing, ${ }^{79,80}$ or reduced function on saccadic velocity testing, ${ }^{81}$ then a supermaximal recession of the ipsilateral medial rectus of $15 \mathrm{~mm}$ with a resection of the involved lateral rectus of $10-12 \mathrm{~mm}$ as well as a recession of the contralateral medial rectus of about $9 \mathrm{~mm}$ will produce satisfactory alignment ${ }^{82}$ It will also achieve a small permanent centred field of binocular single vision (BSV) averaging $25^{\circ}$, which is present in the primary position and on down gaze. However, a larger field of BSV averaging $41^{\circ}$ can be achieved with the Jensen procedure, ${ }^{83}$ while total transposition of the superior and inferior rectus to the lateral rectus combined with botulinum toxin injection of the medial rectus produces the largest field of between $51^{\circ}$ and $78^{\circ} .84,85$ Six of 22 patients (27\%) developed a vertical deviation with this procedure ${ }^{86}$ which although more difficult to perform has gained popularity as the preferred surgical method for 'total' unrecovered sixth nerve palsy. ${ }^{84-86}$

Even long-standing contracture of the medial rectus can be relieved with botulinum toxin, thus avoiding surgery to that muscle when simultaneous superior and inferior rectus transposition is required and thereby reducing the risk of anterior segment ischaemia. Supermaximal surgery is of value when botulinum toxin is not available. ${ }^{82}$

Measurement of the field of binocular single vision ${ }^{87}$ has proved to be an excellent method of assessing function, not only after sixth nerve palsies but also following blow-out fractures, dysthyroid eye disease and other forms of acquired incomitant strabismus. The forced duction test and force generation test are particularly helpful in planning management of sixth nerve palsies and should be performed routinely and appropriately graded. ${ }^{79,80}$

\section{ANTERIOR SEGMENT ISCHAEMIA, SCLERAL PERFORATION AND MICROSURGERY}

Anterior segment ischaemia may result in serious ocular sequelae. It is rare, occuring in 30 of 400000 strabismus operations $(0.0075 \%), 16(53 \%)$ of which were associated with a transposition procedure. ${ }^{88}$ Fluorescein angiography has demonstrated that primary surgery on the vertical muscles has a marked effect on the anterior segment circulation producing an iris sector perfusion defect in 33 of 37 eyes (89\%), although subsequent surgery on the vertical muscles does not have the same effect. Medial rectus surgery alone does not produce iris sector hypoperfusion, whereas simultaneous inferior and medial rectus surgery does. The anterior ciliary arteries do not recanalise after primary rectus muscle surgery, but blood flow returns through the deep collateral circulation, with recovery of the iris circulation occurring in most patients within 4 weeks of surgery. Although staged rectus muscle surgery may be safe, it does not prevent anterior segment ischaemia in all patients. ${ }^{89}$

Patients with poor vision in one eye who require strabismus surgery are often understandably reluctant to have surgery on the better eye. In this situation, if surgery on more than two rectus muscles of one eye is necessary, one has to balance the risks of anterior segment ischaemia of that eye with the risks of a scleral perforation of the other eye, should bilateral surgery be performed. Scleral perforation was reported in 728 of 554000 patients (1.3 per 1000 ) undergoing strabismus surgery; of the 728 patients, $9(1.24 \%)$ had permanent visual loss. ${ }^{90}$ The challenge of re-inserting muscles safely has been made much easier by the availability of spatulated needles, and the use of some form of magnification during surgery. While operating 
loupes with longer working distances, higher powers of magnification and superb optics are popular, routine use of an operating microscope with zoom power control between 3 and 10 times magnification has been advocated. ${ }^{91}$ The light source is excellent and a television monitor coupled to the microscope enhances observation and facilitates teaching.

The technique of preserving anterior ciliary vessels during extraocular muscle surgery ${ }^{92-94}$ cannot easily be performed without the microscope. The technique also has a learning curve, and in order to preserve anterior ciliary vessels successfully when they are most needed, the surgeon should use it on a regular basis.

\section{IMAGING DIAGNOSIS OF EXTRAOCULAR MUSCLES}

Computer axial tomography is particularly helpful in distinguishing between slipped and lost muscles, and in identifying the site of a lost muscle. When using magnetic resonance imaging (MRI), the sagittal views clearly define the vertical recti, and cinemode MRI greatly facilitates the assessment of both muscle location and function. ${ }^{95,96}$

\section{ADJUSTABLE SUTURES}

The surgical correction of strabismus may require multiple procedures. Inadequate correction may be seen immediately following surgery, years after surgery, or as part of the progression of a disease process. Equal amounts of surgery for patients with similar deviations result in a range of immediate post-operative corrections. It is therefore impossible to predict accurately the final surgical outcome for an individual patient. It is even more difficult to predict the effect of surgery for patients who have altered anatomy and scarring from previous strabismus, retinal reattachment or orbital surgery, all of whom present a particular challenge. ${ }^{68}$

Adjustable suture modifications to traditional strabismus surgery were introduced to increase the rate of surgical successes and to reduce the frequency of re-operations by eliminating undesirable early post-operative under- or over-corrections. ${ }^{69,97-100}$ These modifications afford the surgeon the chance to place the eyes in the desired alignment in the immediate post-operative period. Rather than place the eyes in an orthotropic position, the goal of the procedure is generally to align the eyes in a position that will produce straight eyes over the long term. ${ }^{98-100}$ In other words, the long-term drift must be anticipated so that the eventual alignment will be optimal. But are the results of using adjustable suture surgery better

Table III. Preferred position after adjustment

Esotropia with fusion potential: align

Exotropia with fusion potential: 5-10 PD of esotropia

Esotropia or exotropia with no fusion potential: 10 PD of esotropia

Vertical deviation with or without fusion potential: align or slightly under-correct

Muscle palsies, myopathies, trauma or restrictive strabismus: maximise the centred field of binocular single vision

$\mathrm{PD}$, prism dioptres. than those of using direct scleral fixation techniques? There is no prospective randomised study directly comparing the two techniques for a variety of ocular motility disorders. Nevertheless the re-operation rate with direct scleral fixation varies from $20 \%$ to $50 \%$, $^{68,69,101}$ but with adjustable suture techniques is much lower varying from $4 \%$ to $12 \% .{ }^{68-70,99-102}$ In a prospective study of 165 patients, surgery was performed for functional indications in 93 and for cosmesis in 72. Even though the muscles were placed at the position considered to be appropriate for the aims of surgery, 73 of $93(78.5 \%)$ in the functional group and 36 of $72(50 \%)$ in the cosmetic group required adjustment post-operatively. ${ }^{103}$ Without adjustable sutures these patients would have had a less satisfactory result, or would have required re-operation.

Guidelines for the preferred position at the end of postoperative adjustment are shown in Table III. ${ }^{70}$ Post-operative drift specifically following adjustable suture strabismus surgery may occur if the adjustable sutures are left in a slack position after adjustment, or if the sutures are adjusted while the effects of either local or general anaesthesia are still in force. Drift may occur after either adjustable suture or scleral fixation strabismus surgery under several other circumstances as listed in Table IV.

Adjustable sutures have come to be highly valued by many strabismus surgeons, and increase the chance for success with a single procedure to approximately $90 \%{ }^{68-70,98-102}$ yet some surgeons use adjustable sutures minimally or not al all. ${ }^{104}$ Why would one not want to position the eyes where one predicts they should be on the first day post-operatively? One really cannot do better than that!

\section{CONCLUSION}

Progress in the treatment of strabismus has been slow when compared with the development of new techniques and instrumentation that have revolutionised surgery of the anterior and posterior segment in recent years. However, better diagnostic techniques, better sutures, more appropriate surgery, prism adaptation tests, botulinum toxin, adjustable sutures and the like, permit more frequent alignment of more patients with fewer operations, improved long-term stability and better vision. Which techniques will stand the test of time is as yet unknown. Nevertheless strabismus management appears to have finally acquired the scientific rigour, technological exuberance and lively spirit of enquiry that has come to characterise ophthalmology as a whole. If this trend continues, and if basic scientists and clinicians maintain their current level of collaborative activity, the challenge of

Table IV. Factors associated with post-operative drift after strabismus surgery

A continually evolving disease process

Unopposed action of the ipsilateral antagonist

Overaction of the contralateral agonist

Poor vision in the involved eye

Previous extraocular muscle surgery

Drift after previous extraocular muscle surgery 
managing strabismus will become even more rewarding than it is today.

Key words: Strabismus, Challenges, Trends, Natural history.

\section{REFERENCES}

1. Nixon RB, Helveston EM, Miller K, Areker SM, Ellis FD. Incidence of strabismus in neonates. Am J Ophthalmol 1985;100:798-801.

2. Archer SM, Sondhi N, Helveston EM. Strabismus in infancy. Ophthalmology 1989;96:133-7.

3. Ing MR. Early surgical alignment for congenital esotropia. J Pediatr Ophthalmol Strabismus 1983;20:11-8.

4. Bateman JB, Parks MM, Wheeler N. Discriminant analysis of congenital esotropia surgery: predictor variables for short- and long-term outcomes. Ophthalmology 1983; 90:1146-53.

5. Rogers GL, Bremer DL, Leguire LE, Fellows RR. Clinical assessment of visual function in the young child: a prospective study of binocular vision. J Pediatr Ophthalmol Strabismus 1986;23:233-5.

6. Robb RM, Rodier DW. Variable clinical characteristics and course of early infantile esotropia. J Pediatr Ophthalmol Strabismus 1987;24:276-81.

7. von Noorden GK. A reassessment of infantile esotropia. XLIV Edward Jackson Memorial Lecture. Am J Ophthalmol 1988;105:1-10.

8. Pratt-Johnson JA. Fusion and suppression: development and loss. 18th Frank Costenbader Lecture. J Pediatr Ophthalmol Strabismus 1992;29:4-11.

9. Parks MM. Congenital esotropia with a bifixation result: report of a case. Doc Ophthalmol 1984;58:109-14.

10. Jampolsky AJ. Some uses and abuses of orthoptics: the present status. In: Symposium on strabismus. Transactions of the New Orleans Academy of Ophthalmology. St. Louis: CV Mosby, 1971:342-65.

11. Arthur BD, Smith JT, Scott WE. Long-term stability of alignment in the monofixation syndrome. J Pediatr Ophthalmol Strabismus 1989;26:224-31.

12. Tychsen L, Lisberger SG. Maldevelopment of visual motion processing in humans who had strabismus with onset in infancy. J Neuro Sci 1986;6:2495-508.

13. Norcia AM, Garcia H, Humphry R, Holmes A, Hamer RD, Orel-Bixler D. Anomalous motion VEPs in infants and in infantile esotropia. Invest Ophthalmol Vis Sci 1991; 32:436-9.

14. Norcia AM, Jampolsky A, Hamer E, Orel-Bixler D. Plasticity of human motion processing following strabismus surgery. Invest Ophthalmol Vis Sci 1991;(ARVO Abstr Suppl):1044.

15. Kaakinen K. A simple method for screening of children with strabismus, anisometropia or ametropia by simultaneous photography of the corneal and fundus reflexes. Acta Ophthalmol 1979;57:161-71.

16. Molteno ACB, Hoare-Nairne J, Parr JC, Simpson A, Hodgkinson IJ, O'Brien NE, Watts SD. The Otago photoscreener: a method for the mass screening of infants to detect squint and refractive errors. Trans Ophthalmol Soc N Z 1983;35:43-9.

17. Jampolsky A. Animated fixation targets for strabismus examination. Trans Am Acad Ophthalmol Otolaryngol 1960;64:213.

18. Jampolsky AJ. Unequal visual inputs and strabismus management. In: Symposium on strabismus. Transactions of the New Orleans Academy of Ophthalmology. St. Louis: CV Mosby, 1978:358-492.

19. von Noorden GK. Amblyopia: basic concepts of current treatment. In: Symposium on strabismus. Transactions of the New Orleans Academy of Ophthalmology. St. Louis: CV Mosby, 1978:1-14.
20. Foster RS, Paul TO, Jampolsky A. Management of infantile esotropia. Am J Ophthamol 1976;82:291-9.

21. Jampolsky AJ, Norcia AM, Hamer RD. Beneficial effects of alternate occlusion on binocular motion processing in infantile esotropia. Paper presented at the 18th Annual Meeting of the American Association for Pediatric Ophthalmology and Strabismus 1992, Maui (in press).

22. Taylor DM. Is congenital esotropia functionally curable? Trans Am Ophthalmol Soc 1972;80:529-76.

23. Ciancia A. La esotropia con limitacion bilateral de la abduccion en el lactante. Arch Oftal B Aires 1962;26:207.

24. Hess JB, Calhoun JH. A new rationale for the management of large angle esotropia. J Pediatr Ophthamol Strabismus 1978; 16:345-8.

25. Prieto-Diaz J. Large bilateral medial rectus recession in early esotropia with bilateral limitation of abduction. J Pediatr Ophthalmol Strabismus 1980;17:101-5.

26. Weakley DR, Parks MM. Results from 7-mm bilateral recessions of the medial rectus muscles for congenital esotropia. Ophthalmic Surg 1990;21:827-30.

27. Weakley DR, Stager DR, Everett ME. 7-Millimetre bilateral medial rectus recessions in infantile esotropia. J Pediatr Ophthalmol Strabismus 1991;28:113-5.

28. Gobin MH. Recession of the medial rectus muscle with a loop. Ophthalmologica 1968;156:25-7.

29. Clark DI, Markland S, Trimble RB. A study to assess the value of Dacron slings in the management of squints which are not amenable to conventional surgery. $\mathrm{Br} \mathrm{J}$ Ophthalmol 1986;70:623-9.

30. Repka MX, Guyton DL. Comparison of hangback medial rectus recessions with conventional recessions. Ophthalmology 1988;95:782-7.

31. Peart DA, Molteno ACB. Effectiveness and predictability of tendon lengthening procedures. Aust NZ J Ophthalmol 1990; 18:401-5.

32. Murray ADN, Calcutt C. The incidence of amblyopia in longstanding untreated infantile esotropia. In: Campos EC, editor. Strabismus and ocular motility disorders. Proceedings of the Sixth Meeting of the International Strabismological Association. London: Macmillan Press, 1990: 45-49.

33. Calcutt $C$. The natural history of infantile esotropia: a study of the untreated condition in the visual adult. Burian lecture. In: Tillson G, editor. Advances in amblyopia and strabismus. Transactions of the Seventh International Orthoptic Congress. Lauf: Fahner Verlag, 1991:3-8.

34. Hiles DA, Watson A, Biglan AW. Characteristics of infantile esotropia following early bimedial rectus recession. Arch Ophthalmol 1980;98:697-703.

35. Hoyt CS, Jastrebski GB, Marg E. Amblyopia and congenital esotropia: visually evoked potential measurements. Arch Ophthalmol 1984;102:58-61.

36. Ketley MJ, Powell CM, Lee J, Elston J. Botulinum toxin adaptation test: the use of botulinum toxin in the investigation of the sensory state in strabismus. In: LenkSchafer M, editor. Orthoptic horizons. Transactions of the Sixth International Orthoptic Congress. 1988:289-94.

37. Watkins SE, Lee JP. The pre-operative predictive value of botulinum toxin $A$. In: Tillson $G$, editor. Advances in amblyopia and strabismus. Transactions of the Seventh International Orthoptic Congress. Lauf: Fahner Verlag, 1991:189-93.

38. Wortham E, Greenwald MJ. Expanded binocular peripheral visual fields following surgery for esotropia. J Pediatr Ophthalmol Strabismus 1989;26:109-12.

39. Harcourt B, Mein J. Early onset esotropia. Doc Ophthalmol Proc Ser 1981;32:79-81.

40. Chavasse FB. Worth's squint, 7th ed. London. Ballière, Tindall \& Cox, 1939:15, 290.

41. Esswein NB, von Noorden GK, Coburn A. Comparison of 
surgical methods in the treatment of dissociated vertical deviation. Am J Ophthalmol 1992;113:287-90.

42. Scott AB. Planning inferior oblique muscle surgery. In: Reinecke RD, editor. Strabismus. New York: Grune and Stratton, 1978:347-54.

43. Elliott RL, Nankin SJ. Anterior transposition of the inferior oblique. J Pediatr Ophthalmol Strabismus 1981;18:35-8.

44. Mims JL, Wood RC. Bilateral anterior transposition of the inferior obliques. Arch Ophthalmol 1989;107:41-4.

45. Kratz RE, Rogers GL, Bremer DL, Leguire LE. Anterior tendon displacement of the inferior oblique for DVD. J Pediatr Ophthalmol Strabismus 1989;26:212-7.

46. Reinecke RD. Refracting the amblyopic patient. Audiodigest Ophthalmol 1978;16:15.

47. Michaels DD. Visual optics and refraction: a clinical approach. 3rd ed. St. Louis: CV Mosby, 1985:305.

48. Swan KC. Accommodative esotropia long-range follow-up. Ophthalmology 1983;90:1141-5.

49. Helveston EN. Accommodative esotropia. In: Pediatric ophthalmology and strabismus. Transactions of the New Orleans Academy of Ophthalmology. New York: Raven Press, 1986:111-8.

50. Dickey CA, Scott WE. The deterioration of accommodative esotropia: frequency, characteristics and predictive factors. J Pediatr Ophthalmol Strabismus 1988;25:172-5.

51. Symposium on the management of fully accommodative esotropia. In: Campos EC, editor. Proceedings of the Sixth Meeting of the International Strabismological Association. London: Macmillan Press, 1991:269-305.

52. Gobin MH, Bierlaagh JJN. Four-muscle surgery in V-esotropia with longterm orthoptic follow-up. In: Moore S, Mein J, Stockbridge L, editors. Orthoptics: past, present and future. Transactions of the Third International Orthoptic Congress, Miami: Symposia Specialists, 1976:427-40.

53. Gobin MH. Nouvelles conceptions sur la pathogénie et le traitement du strabisme. J Fr Ophthalmol 1981;4:7-18.

54. Gobin MH. Long-term results of the surgical correction of accommodative squint. In: Lenk-Schafer $\mathbf{M}$, editor. Orthoptic horizons. Transactions of the Sixth International Orthoptic Congress, Harrogate, England. 1988:403-6.

55. Gobin MH. The surgical correction of accommodative esotropia. In: Tillson G, editor. Advances in amblyopia and strabismus. Transactions of the Seventh International Orthoptic Congress. Lauf: Fahner Verlag, 1991:105-9.

56. van Nouhuys-Leenders J, Vleeming-de Jong I, Knijnenburg-Gaillard H, Bijker F, van Es-Gutter M, Barenbrug L, et al. Simultaneous horizontal and vertical surgery in V-esotropia. In: Tillson G, editor. Advances in amblyopia and strabismus. Transactions of the Seventh International Orthoptic Congress. Lauf: Fahner Verlag, 1991:84-8.

57. von Noorden GK, Avilla C W. Clinical observations in refractive accommodative esotropia. In: Tillson G, editor. Advances in amblyopia and strabismus. Transactions of the Seventh International Orthoptic Congress. Lauf: Fahner Verlag, 1991:197-201.

58. Mein J, Trimble R. Diagnosis and management of ocular motility disorders. 2nd ed. London. Blackwell Scientific, 1991:213-26.

59. Prism Adaptation Study Research Group. Efficacy of prism adaptation in the surgical management of acquired esotropia. Arch Ophthalmol 1990;108:1248-56.

60. Scott AB. Botulinum toxin injection of eye muscles to correct strabismus. Trans Am Ophthalmol Soc 1981;79: 734-70.

61. Scott AB. Botulinum toxin treatment of strabismus. Focal points: clinical modules for ophthalmologists. San Francisco: American Academy of Ophthalmology, 1989; $7: 1-11$.

62. Scott AB, Magoon EH, McNeer KW, Stager DR. Botulinum treatment of childhood strabismus. Ophthalmology 1990;97:134-8.
63. Scott WE, Reese PD, Hirsch CR, Flabetich CA. Surgery for large-angle congenital esotropia: two versus three and four horizontal muscles. Arch Ophthalmol 1986; 104:374-7.

64. Kushner BJ, Morton GV. A randomized comparison of surgical procedures for infantile esotropia. Am J Ophthalmol 1984;98:50-61.

65. Helveston EM, Ellis FD, Schott J, Mitchelson J, Weber JC, Taube S, Miller K. Surgical treatment of congenital esotropia. Am J Ophthalmol 1983;96:218-28.

66. Mims JL III, Treff G, Kincaid M, Schaffer B, Wood R. Quantitative surgical guidelines for infantile esotropia. Binocular Vis 1985;1:7-22.

67. Ing MR. Botulinum alignment for congenital esotropia. Trans Am Ophthalmol Soc 1992;90:361-7.

68. Wisnicki HJ, Repka MX, Guyton DL. Re-operation rate in adjustable strabismus surgery. J Pediatr Ophthalmol Strabismus 1988;25:112-4.

69. Metz HS. Adjustable suture strabismus surgery. Ann Ophthalmol 1979;11:1593-7.

70. Keech RP, Scott WE, Christensen LE. Adjustable suture strabismus surgery. J Pediatr Ophthalmol Strabismus 1987;24:97-102.

71. Metz H, Mazow M. Botulinum toxin treatment of acute sixth and third nerve palsy. Graefes Arch Clin Exp Ophthalmol 1988;226:141-4.

72. Guibor GP. Squint and allied conditions. New York: Grune and Stratton, 1959:249-50.

73. Jampolsky A. Management of acquired (adult) muscle palsies. In: Symposium on neuro-ophthalmology. Transactions of the New Orleans Academy of Ophthalmology. St. Louis: CV Mosby, 1976:157-8.

74. Rush JA, Younge BR. Paralysis of cranial nerves III, IV, VI: course and prognosis in 1000 cases. Arch Ophthalmol 1981;99:76-9.

75. Murray ADN. Early and late botulinum toxin treatment of acute sixth nerve palsy. Aust NZ J Ophthalmol 1989; 17:239-45.

76. Murray ADN. Early botulinum toxin treatment of acute sixth nerve palsy. Eye 1991;5:45-7.

77. Wagner RS, Frohman CP. Long-term results: botulinum for sixth nerve palsy. J Pediatr Ophthalmol Strabismus 1989;26:106-8.

78. Martonyi JE. Pediatric sixth nerve palsy: case reviews and management guidelines. Am Orthopt J 1990;40:24-31.

79. Scott AB. Active force tests in lateral rectus paralysis. Arch Ophthalmol 1971;85:397-404.

80. Scott AB, Kraft SP. Botulinum toxin injection in the management of lateral rectus paresis. Ophthalmology 1985;92:676-83.

81. Metz HS, Scott AB, O’Meara DM, Stewart HL. Ocular saccades in lateral rectus palsy. Arch Ophthalmol 1970;84:453-60.

82. Murray ADN. Supermaximal surgical treatment of total sixth nerve paralysis. In: Khoo CY, editor. New frontiers in ophthalmology. Proceedings of the Twenty-Sixth International Congress of Ophthalmology. Amsterdam: Elsevier, 1991:970-2.

83. Cline RA, Scott WE. Long-term follow-up of Jensen procedures. J Pediatr Ophthalmol Strabismus 1988;25:264-9.

84. Rosenbaum AL, Kushner BJ, Kirschen D. Vertical rectus muscle transposition and botulinum toxin (Oculinum) to medial rectus for abducens palsy. Arch Ophthalmol 1989;107:82-3.

85. McManaway JW III, Buckley EG, Brodsky MC. Vertical rectus muscle transposition with intraoperative botulinum injection for treatment of chronic sixth nerve palsy. Graefes Arch Clin Exp Ophthalmol 1990;228:401-6.

86. Fitzsimons R, Lee JP, Elston J. Treatment of 6th nerve palsy with combined botulinum toxin chemodenervation and surgery. Ophthalmology 1988;95:1535-42. 
87. Feibel RM, Roper-Hall G. Evaluation of the field of binocular single vision in incomitant strabismus. Am J Ophthalmol 1974;92:382-6.

88. France TD, Simon JW. Anterior segment ischaemia syndrome following muscle surgery: the AAPOS experience. J Pediatr Ophthalmol Strabismus 1986;23:87-91.

89. Olver JM, Lee JP. Recovery of anterior segment circulation after strabismus surgery in adult patients. Ophthalmology 1992;99:305-15.

90. Simon JW, Lininger LL, Scheraga JL. Recognised scleral perforation during eye muscle surgery: incidence and sequelae. J Pediatr Ophthalmol Strabismus 1992;29:273-5.

91. Veronneau-Troutman S. Strabismus microsurgery. In: Jakobiec FA, Sigelman J, editors. Advanced techniques in ocular surgery. Philadelphia: WB Saunders, 1984:667-79.

92. Carlson MR, Jampolsky AJ. An adjustable transposition procedure for abduction deficiencies. Am J Ophthalmol 1979;87:382-7.

93. McKeown CA, Lambert MH, Shore JW. Preservation of the anterior ciliary vessels in extraocular muscle surgery. Ophthalmology 1989;96:498-507.

94. Vila-Cora. Vascular microdissection in strabismus surgery. Arch Ophthalmol 1990;108:1034-6.

95. Nishida Y. The observation of eye movement using magnetic resonance imaging. In: Campos EC, editor. Strabismus and ocular motility disorders. Proceedings of the Sixth Meeting of the International Strabismological Association. London: Macmillan Press, 1990:137-42.

96. Nukina K, Nishida Y, Nishida E, Hayishi O, Mekeda A,
Inatomi A, Kaami K. The observation of movement within the orbit using cinemode MRI. In: Tillson G, editor. Advances in amblyopia and strabismus. Transactions of the Seventh International Orthoptic Congress. Lauf: Fahner Verlag, 1991: 318-21.

97. Jampolsky AJ. Strabismus reoperation techniques. Trans Am Acad Ophthalmol Otolaryngol 1975;79:704-17.

98. Jampolsky AJ. Current techniques of adjustable strabismus surgery. Am J Ophthalmol 1979;88:406-18.

99. Rosenbaum AL, Metz HS, Carlson M, Jampolsky AJ. Adjustable rectus muscle recession surgery. Arch Ophthalmol 1977;95:817-20.

100. Weston B, Enzenauer RW, Kraft SP, Gayowsky GR. Stability of the post-operative alignment in adjustable-suture strabismus surgery. J Pediatr Ophthalmol Strabismus 1991;28:206-11.

101. Kettleman WT, Mazow ML. Re-operations in esotropia surgery. Ann Ophthalmol 1986;18:174-7.

102. Pratt-Johnson JA. Adjustable-suture strabismus surgery: a review of 255 consecutive cases. Can J Ophthalmol 1985;20:105-9.

103. Rosen P, Morris R, McCarry B, Fells P, Lee J. Variability following adjustable suture strabismus surgery. In: Tillson $\mathrm{G}$, editor. Advances in amblyopia and strabismus. Transactions of the Seventh International Orthoptic Congress. Lauf: Fahner Verlag, 1991:89-93.

104. Nelson LB. Reassessment of adjustable sutures in strabismus surgery. In: Laibson PR, editor. The yearbook of ophthalmology. St. Louis: CV Mosby, 1991:175-8. 